\title{
Three strategies for attaining legitimacy in policy knowledge: Coherence in identity, process and outcome
}

\begin{abstract}
In a time where truth and facts are highly contested, understanding how knowledge gains legitimacy is crucial. Creating valuable policy knowledge involves navigating 'a space between fields', where actors and ideas from different social worlds come into play. This paper outlines a novel set of strategies for attaining legitimacy within this space. Drawing on mixed-methods analysis of interview and publication data from twelve development research organizations, the paper argues that legitimacy centres around three primary types of 'coherence'. Coherence in identity is the demonstration of 'proper' goals via negotiation of organizational and individual identity. Coherence in process is the demonstration of 'proper' processes through maintenance of independence, integrity and transparency. Coherence in outcome is the demonstration of 'proper' outcomes via creation of the 'right' products, audience and impact. Mastery of these three areas makes possible the production of credible, distinctive and significant knowledge.
\end{abstract}

\section{Keywords}

This is the author manuscript accepted for publication and has undergone full peer review but has not been through the copyediting, typesetting, pagination and proofreading process, which may lead to differences between this version and the Version of Record. Please cite this article as doi: $10.1111 /$ padm.12385

This article is protected by copyright. All rights reserved. 
Knowledge, Organization, Strategy, Research, Policy

This article is protected by copyright. All rights reserved. 


\section{Three strategies for attaining legitimacy in policy knowledge: Coherence in identity, process and outcome}

\section{Introduction}

The current climate of 'alternative facts' and 'post-truth politics' illustrates how empirical observations can carry little weight against emotion, preconception and power. There are always competing ways of understanding phenomena, what is important is how we decide which are most likely to be true. Empirical observations must be weighed against one another using established theories and methods. Yet there is an ongoing battle for legitimacy over truth and facts, whereby traditional experts seek to adhere to 'the rules of the game', bringing established forms of evidence to bear on economic, social and environment issues, while others attempt to change the rules to their advantage (Fuller 2017). In this context, people across the world have fought to have the role of evidence and expertise in society recognized and reinforced (e.g. the 2017 March for Science rallies). The legitimacy of experts and knowledge is therefore an especially pertinent issue, and we need to ensure we have wellfunded institutions and credible researchers that can provide the most sophisticated ways of understanding pressing issues so that appropriate actions can be taken. As such, examining how knowledge is produced by research actors tasked with informing public policy and debate, and how this knowledge gains legitimacy, is crucial.

This paper offers a novel way of conceptualizing legitimacy in policy-focused research contexts. Legitimacy is defined by Suchman (1995, p.574) as a 'generalized perception or 
assumption that the actions of an entity are desirable, proper, or appropriate within some socially constructed system of norms, values, beliefs, and definitions'. A body of research specifically takes up the issue of legitimacy within the structural environments that research organizations are embedded in (e.g. Marnoch et al. 2000; Contandriopoulos et al. 2004;). According to this thinking, research organizations are a heterogeneous group with a wide range of potential outcomes, where external factors (e.g. norms, relationships, or politics) create pressures to which organizations must adapt (Burns and Scapens 2000; DiMaggio and Powell 1991; Scott 2014). In this view, the purpose of the rules and procedures employed by organizations is to gain legitimacy, rather than to ensure efficiency (Peters and Pierre 1998; Zucker 1977). Prescribed by national, institutional and disciplinary context, organizational actions are therefore based on patterns that develop over time as a result of rules, qualifications and shared beliefs. Thus, informal cultural practices and rituals become as important as technical processes and resource requirements. The attainment of legitimacy is important for organizations because a critical mass is required to attain the resources necessary for an organization's existence and growth, and because legitimacy provides moral authority to operate (Nicholls and Cho 2006). In addition, with the continued importance of evidence-based policy, policymakers (at least rhetorically) turn to scientific evidence for legitimacy, which is no longer guaranteed by purely political processes (Sanderson 2002; Sullivan 2011). It is therefore possible to comprehend the effects of these values and norms on the intellectual labour designed to gain legitimacy through intellectual interventions.

Yet, traditional views of legitimacy (e.g. DiMaggio and Powell 1991; Scott 2014) tend to assume a relatively static field of inquiry where people follow mutually understood norms, 
and actors risk portrayal as cultural dopes. However, there is a recent body of work that takes the production of knowledge as a more dynamic process that is often created in the space between different fields (Eyal and Pok 2011; Stampnitzky 2013). In this space, there are no specific 'rules of the game' or fixed 'capitals' (Bourdieu 1985), but rather shifting, permeable borders that permit actors, ideas, and tools to travel between varied sites of knowledge production (Eyal and Pok 2011). Rather than viewing all fields as tightly bounded spaces, attention should be given to the boundaries between fields, which both separate and connect them. This perspective allows us to conceive the act of producing policy or applied knowledge, or creating meaningful intellectual interventions, as necessarily spanning distances between social worlds.

Researchers and organizations in these contexts are required to manage and satisfy evaluators, funders and supporters from diverse fields, in order to foster and maintain a favourable 'set of symbolic beliefs' in numerous audiences (Carpenter 2010; Gilad, Maor, and Bloom 2015; Maor 2011), whilst attending to a central mission. Derived from an organization's outputs, expertise, principles and procedures, this reputation-based power 'rests in the judgment of its audiences [who] have a form of power, too, as their assessments may diminish if the organization's behaviour exhibits a lack of propriety, equanimity, or honesty' (Carpenter, 2010, p.18). Intellectual products must therefore fulfil the expectations of specific social worlds, while retaining the flexibility to inhabit multiple overlapping communities (Star and Griesemer 1989). Recognizable formats and structures allow them to maintain a common identity across different sites, but each output is also a short-term activity where several worlds intersect (Garrety 1998). Outputs are thus artefacts of specific settings, 
the wider social milieu, and the intended audience. At any stage, research actors must inscribe knowledge, compile evidence and gain resources in balance with diverse audiences with competing interests and rules of the games (Bourdieu 1985).

This paper considers the making of policy knowledge utilizing evidence from several case studies of diverse research contexts. It argues that in order to speak to these different fields, policy researchers are perpetually involved in 'a great negotiation', which takes place between disciplines, professions and sites of production (e.g. Gulbrandsen and Smeby 2005; Denis et al. 2015). For example, the researcher is simultaneously (and unevenly) an academic, journalist, advisor and fundraiser (Medvetz 2010), and is thus engaged in momentto-moment positioning and repositioning in order to establish credibility in relevant fields. Positions are established in the act of self-positioning or positioning of others, and are constantly in flux. Given the diverse aims and interests involved in shifting knowledge into wider society, researchers must increasingly become 'brokers' (McLennan 2008; Kislov et al. 2016). The challenge for researchers is to balance the needs of external actors with the legitimate positioning of their individual and organizational identity and products. Thus, it is crucial to take into account the identity and principles of the actors being studied (Lasswell 1948), but equally important to examine how those actors maintain relationships with relevant 'networks of audiences' (Busuioc and Lodge 2016). In this way, reputational concerns are paramount, shaping how actors 'selectively focus their activities and responses' (Busuioc and Lodge 2016, p. 99). Thus, this paper takes researchers as skilled negotiators, who must appease supporters, partners and regulators, whilst maintaining the credible positioning of their individual and organizational reputation and interventions (Baert 2012). 
Given the necessarily hybrid nature of the space between fields, it is difficult to neatly conceptualize the ongoing negotiation that takes place within these boundary positions. This paper explores legitimacy within these frontiers, in order to account for the strategies that are employed and adjusted by research actors in its pursuit. The strategies of language and action of those operating within these boundary locations are viewed through Suchman's (1995) cognitive, pragmatic and moral legitimacy. Cognitive legitimacy is relatively subtle; it is attained when an organization pursues goals that are taken for granted as 'proper' and 'desirable'; moral legitimacy is gained when activities are conducted as they should be, regardless of the results achieved (i.e. when all activities are in the interest of stakeholders); and pragmatic legitimacy is the social benefit actually created by the organization (i.e. where expected results are not produced, legitimacy is compromised). Actors within different contexts can be seen as vying for and attaining combinations of these types of legitimacy. Thus, it relies upon knowledge production processes matching implicit expectations of the performance and purpose of knowledge. Therefore, the result of successful research practices, however defined by the context or field at hand, is the achievement of legitimacy. Moreover, because the goal for each context is long-term sustainability, especially given increasingly short-term funding, the research or analysis processes must be replicable over time, to continue responding to the needs of principal stakeholders and so maintaining legitimacy (Mason et al. 2007). Thus, in policy and practice-oriented fields, research becomes about the strategies of action and language which create audiences and increase the value, legitimacy and thus, ultimately, the effects of particular interventions across fields. 
By considering discursive accounts of knowledge production and the types of interventions produced across three policy research contexts - university departments, think-tanks and government agencies in international development - the paper examines how individuals and organizations gain legitimacy through strategic language and action. It examines how knowledge is shaped by disciplinary, professional and organizational structures and intended publics in the space between established fields. In setting out three strategies for attaining legitimacy, the paper provides an account of what types of knowledge are valued and legitimized, offering insights into what comes to constitute truth in policy and politics. The paper addresses the following question: What types of knowledge are valued across contexts, and how is legitimacy gained through the production and dissemination of particular types? It considers narratives of the processes of policy research, and the types of intellectual interventions being produced. This perspective provides a novel account of the ongoing strategic negotiation involved in producing knowledge within the space between fields, where the priorities and values of diverse social worlds must be simultaneously managed.

\section{Methodology}

\section{Case selection and characteristics}

This study sought to operationalize the concepts developed by Eyal and Pok (2011) and Baert (2012); examining the boundary locations of knowledge and expertise between established disciplines, professions and fields, and the positions, strategies and structures that govern the ongoing negotiation between intellectual products, their context and their recipients. On a theoretical level, this research is a study of the positions, strategies and interventions within a 
space between fields. On a methodological level, it is an empirical study of the discourse and outputs produced by universities, think-tanks and government research agencies within Australian, British and multilateral contexts. This reflects the growing tendency of policy knowledge to comprise interactions of experts across national borders and involve multiple states and international institutions (Stone 2008, p.19). Although transnational features have largely been neglected within the study of spaces between fields, I sought to draw out observations that span country contexts, while allowing for specific national settings that shape knowledge production. The paper presents a mixed methods investigation of knowledge production across twelve policy-focused research sites.

The cases were chosen because they have established policy-relevant research programmes in international development, and a critical mass of high-quality analytical projects on development issues. For the four university contexts, I selected two research leaders and two with alternative outlooks (one with a primary focus on teaching and another with a heterodox, critical perspective). For the four think-tanks, I selected two with university affiliations and two with alternative models (one with diverse policy/research areas not limited to international development, and another 'consultancy-type' with an exclusive focus on development). For the government agencies, I selected two bilateral agencies as well two dominant multilateral agencies (one with a centralized research department and one without). Accordingly, the cases display variations in funding, formal requirements, and evaluation approaches. These features are important, because different institutional actors develop their strategies according to the particular conditions they exist in. 
For the four university departments, staff numbers ranged from 8 to 65 , and funding was primarily from government bodies, with additional funds from charities, research councils and the private sector. For the four think-tanks, staff numbers ranged from 49 to 235 , and funding took the form of research grants, contributions from philanthropic foundations, individuals and governments, sale of knowledge services, teaching, trading and membership fees. For the four government agencies, exact staff numbers were unable to be attained, given the non-publication of researcher lists. Funding for these four cases came from internal programme budgets. The cases were selected to account for expected differences in research production, use and evaluation across contexts. Although there exists considerable variation between specific research settings, this paper seeks to provide evidence of general patterns of strategy development across research contexts. This framework can then facilitate examination of the specific relationship of an organization to its milieu.

\section{Data analysis}

I conducted discourse analysis of interview data, document analysis of institutional content and quantitative analysis of publication data. The combination of discursive practices and intellectual products allowed examination of intellectual production across research contexts, rather than binding actors to a specific one. Information was collected about many different aspects of the institutions via 75 interviews with researchers, collation of documents or online artefacts that gave a sense of institutional 'character' or 'identity' (i.e. annual and financial reports, website content, blog entries, key policy papers and evaluations), and bibliometric use of publication lists and academic databases. 
Qualitative analysis of interview and document data began with the categorization of transcripts/documents via MAXQDA software. The first phase of analysis involved searching for patterns in the data; both variability and consistency in content or form. The textual and contextual properties of positions taken by institutions (and individuals) were systematically examined, and explicit evidence for each account were 'free coded' (assigning segments to unique codes) and 'in-vivo coded' (using key terms from respondents as codes). Of the many potential properties, I focused on those that most clearly displayed the discursive properties of the exercise of legitimacy or struggle over positions within the space between established fields and professions. The second phase of analysis was concerned with identification of functions served by, and consequences of, those patterns in the process of the management of the public consensus on individual or organizational intellectual labour.

Quantitative analysis began with creation of a database of publication data: title, year, date, type, topic, authors, abstract and source. Using an inductively defined categorization of outputs into 'reports', 'articles, news, and blogs', 'working papers', 'briefings', 'books', 'journal articles' and 'other', the data on publication type, date and authors was then cleaned and separated from the main database and graphed. Where funding data was available, I conducted further analyses to identify trends in the production of particular types of outputs. Together, these methods provided a rich account of the types of outputs being produced, and the ways in which these are valued by the research context and wider field.

\section{Results and Discussion}


This paper argues that the demonstration of legitimacy centres around three primary types of 'coherence', outlined in Table 1, which broadly map onto Suchman's (1995) categories of legitimacy.

\section{[TABLE 1 GOES HERE]}

The manifestation of these concerns varies within and between research contexts. Each organization and context has its own internal logic, arising from its location in the space between fields. For example, for think-tanks in my sample, a common concern was potential incongruence arising from donor influence over organization mission, whereas for universities, incongruence could arise from the 'wrong type' of intellectual product (e.g. policy brief) which is not an 'acceptable' academic output. I have sought to draw out the conditions under which these different institutional actors develop their strategies, but also to indicate where there is more ritualized discussion (e.g. common tropes around impact). Each type of coherence will be addressed in turn. Longer quotes are provided in the appendix, indicated with a reference (for instance, 'EG1').

\section{Coherence in identity}

This section argues that in order to gain cognitive legitimacy (i.e. 'proper' goals), research actors seek coherence through negotiation of organizational identity and individual identity, which, in turn, affords distinctiveness. 


\section{Negotiating organizational identity}

A key task for individuals and organizations across contexts was to negotiate a coherent organizational identity. Participants' descriptions of institutional identities aligned to varying degrees with organizations' self-positioning through public documents and outputs. There was a spectrum of available identities, from tightly to loosely bound to particular ideals (Tchillingrian 2015). On the tightly bound side of the spectrum, researchers often reinforced their institution's public statements to develop an identity that is stable and laudable, and thus dedicated to ideals. For example, academics from one department often cited a collective heterodox perspective (EG1). Researchers also described a process where institutional identity becomes reified as the organization is professionalized 'because there's pressure to have a position and to engage with the media so you've got to adopt key messages' (EG2). A coherent identity was also strongly bound up in specialization or discipline, for example where an economics-focused government institution made a 'shift to more neoliberal values' (G21). On the loosely bound side of the spectrum, researchers across contexts often positioned their (and other) organizations as malleable, able to adapt their institutional identity as required (e.g. by funders, stakeholders). For example, some researchers highlighted individual freedom in spite of organizational consensus. One think-tank researcher described: '[There is no] particular ideology the Institute promotes [and] individual scholars could choose their own position and argue it' (EG3). In these cases, some were positioned as successfully straddling the social worlds of research, policy and practice, and others denigrated for embracing 'too-flexible' consulting models. The two sides of the spectrum, from tightly to loosely bound to particular ideals, reflect tension between the long- 
and short-term strategies of an organization, for example, where a fixed 'neutral' position must be balanced with 'autonomy' in the face of multiple external interests (EG4).

A coherent identity permits organizations to be located within the space between fields. The organization thus takes on a character beyond its constituent individuals. For example, one multilateral researcher (G8) described 'a lot of internal stuff, basically in terms of keeping the organizational goals high on the radar'. A consistent institutional identity thus simultaneously confers organizational benefits and constrains researchers' autonomy (Tchillingrian 2015).

On the one hand, a cultivated brand can influence how intellectual interventions are received. On the other, a brand can also shift researchers towards particular positions and limit internal diversity. This was evidenced by researchers indicating that certain types of outputs would be viewed as inappropriate or illogical (i.e. a concern with staying inside the organization's legitimate bounds). This was less evident within university departments, where greater diversity was expected. However, researchers across contexts demonstrated a preoccupation with the organizational brand, and a requirement to maintain congruity.

The process through which these brands are negotiated and interpreted internally and externally differs between research contexts. This has to do with the function of organizational hierarchies, and the extent to which these are involved in maintaining organizational cohesiveness and identity. In university contexts, researchers described greater autonomy to pursue personal goals, unusual avenues of funding, or side projects; their constraints relate to the need to acquire funds and achieve publication rather than overt monitoring by organizational hierarchies. In think-tanks and government agencies, however, 
formal and informal hierarchies shape decision making more strongly. Directors, managers (and to some extent, colleagues) have the power to define certain activities and avenues as outside the organization's key aims, and thus to determine what is ultimately represented in the organizational identity.

\section{Negotiating individual identity}

Individual researchers also self-position in relation to their own and other organizations. Researchers displayed an awareness of how their own institution (and wider context) are perceived, and often invoke other organizations to define the bounds of their own intellectual production. Thus, individual congruence with institutional documents and official language is not a given, as researchers can resist elements of their institutions to achieve specific discursive outcomes. For example, researchers within multilateral agencies often positioned themselves as cognitively autonomous from the 'neoliberal agenda' of their institutions. However, an organization's location in the field does have implications for available individual positions. Thus, an organization's history of ideological and epistemological positions is a key factor in shaping intellectual interventions or outputs. Each of these elements is constantly negotiated by way of a researcher's idiosyncratic conception of the research or policy field. Organizational brands therefore do not directly constrain; rather, a number of internal mechanisms keep ideas within preferred parameters. I have identified two negotiations - the research agenda and feedback - where this occurs.

In the first case, institutional parameters permeate the decisions of individual researchers is through the processes of defining, identifying and setting research agendas. Researchers 
across contexts describe the process of selecting research questions as more bottom-up than top-down. One government researcher characterized the mix of processes: 'Number one is what I observe as problems in the world, number two, what seems to be of interest to the institution, and number three, what my various expertises are' (EG5). In this context, individual researchers 'don't have complete freedom but certainly have many opportunities to import ideas' (EG6). Thus, internal structures simultaneously constrain and enable individual flexibility. One multilateral researcher (G15) noted 'I wouldn't say there is complete freedom to just decide what topics we are going to research, but it also needs to fit with what the institution feels is important'. Overall, while universities largely seem to have retained a sense of academic freedom, in think-tanks and government agencies, an organization's broad research aims are (jointly) established in advance. Thus, researchers have a certain freedom, moderated to a greater extent in think-tanks and government contexts and to a lesser extent in universities. In the former, these controls are formal and informal interaction with colleagues and managers, whereas in universities, controls relate to funding, collaboration and interest in research topics. Thus, authority over agenda is also authority over organizational identity.

The second key way that institutional parameters permeate the decisions of individual researchers is through feedback processes. The role of feedback and advice is crucial in maintaining organizational identity. For university departments and university-affiliated think-tanks this often takes the form of informal un-hierarchical teams. In academia, formal peer review was key, but also relevant were loose networks that provide feedback, ideas and editing support. Here, coherence with the organizational brand was subordinate to coherence with individual brand (i.e. consistency with previous publications and public statements), 
however there was some degree of external brand 'checking'. Thus, there seems to be greater freedom for intellectual dissent or divergence (e.g. describing their work as being unproblematically 'marginal'; T5). Critical feedback was especially salient for (nonuniversity-affiliated) think-tanks and government research agencies (EG7). As we saw above, organizational hierarchies shape research agendas through meetings with directors/managers. In addition, institutions rely on other touch points where intellectual labour is shaped and refined. For example, late-stage feedback meetings often take place to polish outputs, suggest links to previous internal work, and ensure consistency with other messages/arguments put forward by the organization (EG8). Think-tanks and government agencies manage the risk of conflicting policy proposals through formal and informal monitoring and feedback processes. Larger organizations, such as multilaterals, tend to operate on a more formal basis, whereas smaller organizations, such as niche advocacy think-tanks, tend to rely on informal ongoing assistance and mutual feedback.

This section demonstrated how the interaction of an organization's identity and researchers' conception of the field shapes distinctive intellectual production. Cognitive legitimacy thus requires ongoing negotiation of a coherent identity, bounded by a balance of bottom-up and top-down processes.

\section{Coherence in process}


This section argues that in order to gain moral legitimacy (i.e. 'proper' processes), research actors must display coherence through maintaining independence, integrity and transparency. This, is turn, affords credibility.

\section{Maintaining independence}

In order to create legitimate policy knowledge, actors must maintain 'proper' relationships with the wide range of external actors in the development space. Key amongst these, in terms of legitimacy, is 'independence' from funders. Researchers from university departments with a high degree of core funding, and 'ivory tower' reputations, are relatively unconcerned with demonstrating independence from external funders. By contrast, university departments with greater external funding display similar strategies to university-affiliated think-tanks for maintaining independence (e.g. emphasizing rigour). Within think-tanks, there is an everpresent tension around project-specific funders. For example, a university-affiliated thinktank director compared its consultancy and academic arms: 'The important feature of doing research-based consultancy policy advisory work is that the people you're working with have a sense of ownership of what you're doing' (EG9). All contexts were aware of 'how it looks' to take money for individual projects, and stressed that this was either not the case (e.g. donations were spread across projects or years) or that the risk of 'external ownership' had been mitigated in some way. The mitigating factors included: commitment to the ideals of independent analysis, internal peer review processes, and crucially, at each project's outset, explicitly emphasizing editorial control in negotiations with funders. 
Within government agencies however, there is a markedly different relationship to funding. Researchers from these organizations go through an internal funding pool, but reported relative ease in gaining support for good ideas. However, these researchers cited pressures arising from the nature of the institution itself. A multilateral researcher described internal pressure where 'people want to see their programme featured in a positive light, the administrative teams want things happening on the right timeline and so certainly there are pressures there that I think an independent researcher at a university setting would not face' (EG10). Rather than demonstrating that they are not being unduly swayed by external interests, researchers from these contexts were concerned with demonstrating scientific objectivity or cognitive autonomy in the face of political/bureaucratic pressures. Crucially, they were also eager to demonstrate they are not beholden to organizational ideology, often perceived to be aggressive or hegemonic. Given the size and power of these institutions, these researchers seek ideological independence from 'internal funders'. In this way, individuals can position themselves as outside the brand, while recognizing that their products operate within its boundaries.

Researchers across contexts, whether acting as consultants or 'traditional' academics, were strongly oriented towards the goal of objective systematic work. They displayed an awareness, and resignation, that funding arrangements could (be seen to) impinge on this 'ideal-type' research. In their accounts of the research process, researchers engaged in ongoing attempts to head off potential accusations that funding might devalue their scientific inquiry. Researchers across all contexts emphasized a concern with legitimate, independent products, and sought to prevent any possible charges of patronage or dependency. 


\section{Maintaining integrity}

There are a range of ways in which actors challenge, or attempt to challenge, the priorities of the funders they do engage. This is reinterpreted here as a means of attaining legitimacy through 'integrity'. Researchers in my sample described a core group of funders, with specific interests and varying levels of assertiveness over research practices. For example, interviewees expressed 'resignation' towards bilateral attempts at control over research contracts. One characterized the problem as 'not just about the research funding, but it's about the things that you need to do to get it', whereby there is a tapering of research topics in line with funders' goals (U13). One senior university researcher (U9) described a 'narrowing of the agenda', which 'pushes you away from some more radical ideas'. These sentiments were echoed by a government researcher: ' ...money comes with strings. But the strings are quite delicate, if there are any, in the sense that obviously researchers have a choice about whether they want to apply for research funding and [what] to focus on' (EG11). Here, maintaining integrity in research revolves around exercising 'choice', which locates responsibility with the individual researcher. It is therefore the researcher's obligation to exercise the appropriate strategies in resisting funders' interests, either by choosing not to work with a particular funder, by choosing to pursue a particular type of funding arrangement, or by paying particular attention to the nature of the contract.

Thus, rather than direct funder pressure, researchers reported a squeeze on the direction and focus of research, thus shaping and regulating policy research. As above in the negotiation of research agendas, this process allows for individual freedom while simultaneously 
reinforcing funder power through the elaboration of specific criteria (Rauh, 2010). In general, participants from university and think-tank contexts displayed a certain level of comfort with the idea that research is necessarily funded by external bodies, as almost all think-tanks must fundraise and many academics take on supplementary consulting projects. The notion that a funder might try to exert influence was anticipated, managed and ultimately negotiated. Even where researchers were critical of the funders themselves, this process was regarded as a 'negotiation' where the rigours of academic work must be reconciled with unavoidable funder pressure. Researchers sought to position their work as upholding one of the two key tenets of policy research; scholarly rigour or political authority (Medvetz 2012). In this way, they could head off potential accusations of their research being simply the creation of marketing materials. For example, one think-tank researcher differentiated: ' $\ldots$ at the end of the day it's your product. It's got your name on it, whereas at the [multilateral] it's a more corporate effort' (EG12). Some degree of defiance is crucial here, as shown in a think-tank example where the funders 'have been unhappy with the type of research that we've been conducting before the results have been out. That's been expressed. We resist very strongly' (EG13). This defiance, which takes the form of a diversified funding base, philanthropic funding, or academic freedom endowed by core funding, is a crucial aspect of university and think-tank (and individual) maintenance of integrity and thus positioning as legitimate. In the case of internal funding in government institutions, this resistance takes the form of the ideals around scholarly production; academic freedom through adherence to the values of sound social scientific practice. 


\section{Maintaining transparency}

A key strategy for attaining legitimacy across contexts occurs via demonstration of transparency. Although university departments and government agencies have in some way been exempt from ongoing negotiation over independence from funders, this appears to be changing. With the rise of consulting research in universities, academics also sought to headoff accusations of 'analysis for hire'. Within universities, transparency requirements take the form of national evaluation frameworks, where detailed financial information is collected, presented and made available to the public. Accordingly, individual departments are not required to detail (external) funders in public documents. In contrast, think-tanks are often criticized in the media for their lack of transparency, and thus organizations often specifically divulged financial information in order to maintain legitimacy (e.g. via 'Transparify' and other ratings). Demonstrating a high degree of transparency is an outward sign of independence from funders. Although government researchers are exempt from demonstrations of financial independence, these contexts are highly concerned with transparency. Specific evaluation departments exist to provide information on the practices of these agencies, and scrutiny is directed to internal research departments. Organizations across contexts therefore outwardly demonstrated their intellectual autonomy, regardless of actual institutional arrangements. Notably, none within my sample rejected the premise of independence or transparency. For example, available arguments that funding is subordinate to the quality of ideas or 'none of the public's business' were not taken up. 
This section demonstrated how research actors negotiate a coherent set of 'acceptable' processes to maintain credibility. It argued that moral legitimacy requires ongoing positioning around independence, integrity, and transparency.

\section{Coherence in outcome}

This section argues that in order to gain pragmatic legitimacy (i.e. 'proper' outcomes), actors must display coherence by creating the 'right' products, audience, and impact. This, in turn, affords significance.

\section{Creating the 'right' type of products}

Although legitimate intellectual products can take many forms, across contexts there was a general commitment to rigorous and robust research underpinned by sound social science practices. Within academic contexts, it was clear that different disciplines, paradigms and epistemologies signal particular standards of credibility, rigour or trustworthiness. Thus, the 'goodness' of inquiry is assessed according to the standards of the discipline (Morrow and Smith, 2000). Think-tanks and government agencies were less oriented to specific disciplinary demarcations but were careful to couch their intellectual products as relying on robust analysis and, crucially, as distinct from the content of a lobbying or campaigning organization. Thus, 'rigour' must be negotiated in the production of legitimate social science.

Researchers within universities were oriented both to 'the global body of knowledge' and the extra-academic market. In university contexts, formal evaluation frameworks prescribe 
particular types of products, and academics described a 'normal kind of academic output', understood to exclude those for wider consumption. Although formal mechanisms incentivize traditional publications (i.e. journals, books, conference papers), analysis of publication data showed researchers did also submit 'marginal publications' (e.g. external reports, working papers) into evaluations. One university researcher described producing 'a lot of popular publications like little two-page developed viewpoints or four-pagers, policy briefs or research briefs, because the idea was we want to have an impact beyond academic circles' (EG14). This suggests that 'marginal outputs' are becoming less marginal, and are increasingly viewed as key means of research communication (Laudel and Gläser 2007). Together, this may reflect shifting notions of good research due to the growing impetus for 'impact'. There is therefore freedom in universities to make genuine public interventions through a range of intellectual orientations, modes of production and output styles.

Within think-tanks and government agencies, methods for evaluating outputs included quantitative metrics, qualitative assessments and expert rankings. These particularly focus on digital channels, which are crucial for marketing ideas, disseminating outputs and establishing expert reputations. Quantitative analysis of think-tank publication data showed that total publications are increasing, likely reflecting growth in institution size and social media/blog use. External reports in all four think-tanks appeared to be increasing, and for the two Australian think-tanks, online articles, news and blogs have markedly increased. These observations correspond to the interviewees' descriptions of their output practices. For example, one think-tank researcher described 'big disincentives ... if you want policy impact you are not going to get it by waiting for something to be published in a peer review journal' 
(EG15). This is paralleled by the experience of another (T15): 'We are not able to get as many articles in scholarly journals as we like, because we move on too quickly to the next contract'. The rise of social media and blogs, especially within Australia, is also notable, with researchers describing increasing use of policy blogs. One researcher (T9) described how Twitter directs traffic and attracts journalists to the think-tank's blog and 'gives us a new audience'.

In contrast, analysis of government outputs suggest that these agencies are primarily focused on policy (e.g. briefings) and practice (e.g. reports), supplemented with a range of other output types, with the exception of one multilateral agency, which focuses equally on academia (e.g. journal articles). These findings support those of large-scale agency research evaluations (ICAI 2014; Young et al. 2015) which show increasing augmentation of policy and practice with skills and approaches of media, business, and academia. Researchers from think-tank and government contexts also emphasized face-to-face meetings, presentations and gatherings for gaining trust and authority and disseminating research to wider audiences.

Overall, these findings suggest some convergence across contexts. Academics increasingly produce 'marginal' extra-academic outputs, think-tanks balance academic, media and political outputs with reports for funders, and government agencies seek to supplement politics by foraying into multiple fields. 


\section{Creating the 'right' audience}

Researchers across all contexts were concerned with producing 'valuable' and 'pertinent' knowledge (juxtaposed with 'abstract' or 'useless'). The extent to which researchers were concerned with performing value varied across contexts. This was less of a concern for academics, who freely described their work as 'critical' or 'theoretical'. Think-tank and government researchers, by contrast, strongly couched their work in terms of value and importance. These discursive features mapped onto a dichotomy of activeness/passiveness in 'pushing' ideas out into the real world. The extent to which researchers 'ought' to actively translate their knowledge into real world outcomes varied across contexts. Academics couched the translation of their work more passively. Here, the value of their work rested on scholarly progress (as assessed by peer review), underpinned by an assumption that good science trickles down into good policy or practice. On the other hand, think-tank and government researchers actively stressed the worth of their work in policy, practice or politics. Legitimacy of this type is thus dependent on research recipients. It is the wider publics' (anticipated) interpretation of intellectual outputs that is critical. Thus, the amount of power held by recipients (i.e. to advance or delegitimize an individual or institutions) depends on the extent of their engagement and competence (Baert 2012). Across contexts, the aim of intellectual products is to persuade stakeholders/decision-makers to adjust their positions in light of research findings and arguments. This takes the form of critical, normative arguments on theoretical, methodological or empirical grounds, or critiques of current conceptual/discursive frameworks, policy positions or development practice. 
There are also key differences between contexts in processes occurring after outputs are written and released. Within universities, notwithstanding a small number of 'isolated' researchers, academics were increasingly concerned with wide dissemination. Many university researchers described discontent with the 'endless cycle' of academic publishing, and often sought to push their work out directly to policymakers and practitioners. Academics commonly reported blogging or engaging in supplementary activities to draw attention to their scholarly work. As one academic reported: 'I write a blog and I know that has been read probably thousands of times more than anything that I have written from an academic perspective' (EG16). However, although university researchers were oriented towards 'public engagement' and 'impact', implementation was often not straightforward. For example, primary outputs (i.e. journal articles) have to be translated into shorter, more digestible forms, which requires time and resources that are often unavailable. Researchers pointed to a lack of resources for 'packaging up' findings in an attractive way that is useful to policymakers or practitioners.

For think-tanks and government agencies, there is a different process after an output has been written and released. The process varies according to a number of factors including the size, resources and academic-orientation of the organization, but often involves a press release or promotional strategy. These are typically constructed by the researcher alongside communications staff, who 'translate' the research in light of policymakers' requirements into a package for media or wider consumption. One think-tank researcher explained: 'We have a media person who is quite effective so we use social media very effectively to get the output out whether it's Facebook or Twitter plus traditional media' (EG17). At this stage, expert 
narratives are secondary to broader set of policy goals, orientations and interests. Thus, researchers relinquish some control over their product. The outcomes usually take the form of a policy document and a social media or press release, at which point the research becomes 'branded'. Think-tanks and government agencies were willing to hand over untethered intellectual products to relevant audiences, and actively promote them. This outward orientation allows think-tanks and government agencies to engage a wide audience, while guarding their identity (e.g. through content, tone, statements) to maintain legitimacy. As such, the processes of knowledge production are not fixed or predetermined. Accordingly, actors can gain legitimacy via multiple strategies that create relevant audiences.

\section{Creating the 'right' kind of impact}

The increasing focus on research impact is a structuring force in the construction of valued, legitimate knowledge. Across contexts, a number of tools are employed to measure impact or influence. Within universities, researchers directed their outputs towards the standards of the community (i.e. citations, journal impact factors), but were also interested in additional indicators of influence and symbolic capital (e.g. ability to sway colleagues or decisionmakers). A number of interviewees also described a preoccupation with altmetrics, that is, download counts, web hits, and media and social media mentions. In universities, a concern around 'making a difference' was couched as 'impact'. An Australian professor described using non-academic indicators 'as a test case for me to see if the University is really going to live up to its rhetoric around wanting to do more of this kind of applied research and making a difference and building partnerships with the outside world as opposed to just making metrics that are largely academically based' (EG18). Impact strongly permeated the language 
and tone of interviewees; a demonstrable connection to policy and practice is a discursive prerequisite to worthwhile intellectual labour, and even those in more theoretical areas must work hard to demonstrate the value of their research.

Within think-tanks, impact or influence took the form of commitment to strategic goals. It related to the fulfilment of organizational mission to create policy or practice change. One think-tank director described that in academia 'there's not enough engagement with the sectors or the processes that are being researched... and it leads to the discrediting of academic research in the eyes of the very people that we should be trying to influence' (EG19). For example, in consultancy-models, their ongoing business (i.e. being awarded new contracts) is taken as evidence of the organization's impact. In advocacy-based think-tanks, however, influence is the ability to 'get the right people in the room'. As with universities, the impact imperative is reinforced by funders who set conditions for commissioned research. A university-affiliated think-tank research director (T1) described a necessary balance: 'If you're doing policy-oriented research you do need to reach out to the policy community'. For government agencies, impact is more nebulous. Interviewees reported uncertainty around intellectual influence within their own organizations (and associated partners, contractors), despite in-house researchers' mandate to fill gaps in decision-makers' knowledge and offer solutions. As one Australian bilateral researcher (G3) stated: 'I don't really feel like I have very much influence over policy anyway'. Yet researchers reported that 'it's important that it has an impact on policy' (EG20). They were invested in 'separating out impact' and reported 'an increasing emphasis on trying to demonstrate the value of investments in research' (G7). 
Rather than a neutral depiction of research requirements, this commitment to impact is also a symbolic tool used in public demonstrations. 'Impact' makes space for actors to position their research as both untainted and useful. Thus, an organization that defines itself as invested in impact is attempting to assert the usefulness of its intellectual labour over others who are "too academic' or 'only academic'. However, to defend this position, the organization must gather evidence through primary research (e.g. metrics) or authoritative 'experts' (e.g. case studies), therefore reinforcing the 'rigour' of the academic world. Despite the preponderance of impact measurement, researchers across contexts expressed discontent with the extent to which their work 'actually' produces change. Accordingly, researchers often described failures of current institutional arrangements in facilitating their mission; academics reported isolation from networks and tools of wider engagement, think-tank researchers described restrictive shortterm fundraising and bemoaned reliance on clients/funders, and government researchers described political posturing and stifling bureaucracy. Thus, it is clear there are differences in the ways impact and influence are understood, and in the ways research actors self-position around their ability to affect social change through legitimate intellectual interventions.

Though undoubtedly reflecting genuine financial and political constraints, these statements around impact are performative. They place intellectual practice at the intersection of different fields (e.g. academia, media and business and politics; Medvetz 2012). Thus, 'impact' is not only the ability to affect (and assess) genuine change via policy or practice, it is also a symbolic tool that demonstrates scholarly proficiency, media savvy, and fundraising ability. Thus, there is diversity in strategies, goals and interests, both within organizations and over time. Narratives around impact thus show how actors reconcile their hybrid intellectual 
practice, and debunk the assumption that the dominant labour of each context is simply an extension of a single field or profession.

This section demonstrated how research actors negotiate a coherent set of 'acceptable' outcomes to establish significance. It argued that pragmatic legitimacy is gained through the deliberate creation of appropriate outputs, audiences and impact.

\section{Conclusion}

In a time where truth and facts are highly contested concepts, traditional experts and sites of knowledge production seek to adhere to 'the rules of the game' via established forms of evidence on social and environmental issues, while others attempt to change the rules to their advantage to emphasize alternative ways of understanding the world. The attainment and maintenance of legitimacy by research actors tasked with informing public policy and debate is therefore a crucial issue. This paper offers a novel way of conceptualizing the strategic negotiation of legitimacy in policy-focused research contexts that exist within the space between fields. For example, cognitive legitimacy is exemplified in think-tanks' ongoing negotiations to balance competing interests to do 'what works' in policy change, moral legitimacy can be seen in the intellectual freedom or 'critical' research of university departments, and pragmatic legitimacy can be accessed by government research agencies invoking a 'pipeline' to decision-makers. Broadly, academic and government actors can rely on established processes of knowledge production, potentially affording more stable 
identities, defined processes and bounded outcomes, whereas think-tanks operate on the periphery.

Yet, the separation of institutions into established research contexts offers an incomplete framework for understanding what types of knowledge are valued and how legitimate knowledge is created. For example, even within individual university departments, opposing forces can articulate incommensurable but equally coherent accounts. Likewise, the negotiation of different types of legitimacy may conflict with one another. For example, coherence in process (moral legitimacy) gained through emphasis of researchers' individual 'choices' may conflict with coherence in identity (cognitive legitimacy) gained through public organizational statements. Crucial also is consideration of situations where coherence is more difficult to perform, or where different actors and different sources of legitimacy may engender incoherence. These organizations and the actors within them do not always succeed in their negotiations. For example, sometimes research impact must be sacrificed for professional or scientific values, and at other times, scientific standing is forfeited. Thus, there is also a need for academic attention on 'incoherence', such as the unavoidable failures, impediments and inconsistencies in pursuing the types of coherence outlined above. This paper thus provides a framework that accounts for the processes of creating legitimate and valued interventions that intervene in the academic, policy and practice worlds, and allows for rich description of where these processes both succeed and fail.

This paper suggested that institutions are not fixed or immutable; they are continually enacted and become 'true' through ongoing interactions. The making of policy research thus occurs as 
a process of negotiation. Research actors across contexts must carve out space for themselves in the intersecting worlds of the space between fields by accessing and developing social capital and status from more established fields, disciplines and professions. Reframed in this way, the structural and cognitive features of each research context make available certain positions, which can be taken up with varying degrees of effort from moment to moment. This process transcends any single community, and given broad structural changes that have seen knowledge production bound up in economic and social challenges, necessarily involves increasingly skilled strategic negotiation between several fields. By permitting descriptions based on the attainment (or otherwise) of three types of coherence, rather than primarily on institutional features, this framework can account for varying standards of good practice within research contexts, which are far from homogenous.

\section{[TABLE 2 GOES HERE]}

This paper sought to elaborate the skilled negotiation required in knowledge production, by elucidating the everyday practices of policy research. It argued that the production of legitimate knowledge centres around three primary types of 'coherence', which depend on the performance of 'proper' identities, processes and outcomes, as shown in Table 2. Ongoing negotiation of each of these elements is required for the production and dissemination of valued knowledge. For cognitive legitimacy, institutional identity must be balanced with that of its constituent individuals. A coherent identity makes intellectual interventions recognizable and distinctive. For moral legitimacy, actors must continually demonstrate independence from external interests, integrity in dealing with others, and 
transparency in institutional arrangements. Coherent processes make intellectual interventions trustworthy and credible. For pragmatic legitimacy, actors must produce the appropriate types of products for relevant audiences and achieve the right kind of impact according to the standards of the community. Coherent outcomes make intellectual interventions accessible, worthwhile and significant. This paper considered the ways research actors navigate the space between fields as they produce knowledge. It thus offered a description of the processes of policy research in order to show how knowledge is shaped into legitimate and valued interventions that affect the academic, policy and practice worlds. 


\section{References}

Baert, P. (2012). Positioning theory and intellectual interventions. Journal for the Theory of Social Behaviour, 42(3), 304-324.

Bourdieu, P. (1985). The genesis of the concepts of habitus and field, in Sociocriticism, 2, 1124.

Busuioc, M. \& Lodge, M. (2016). Reputation and accountability relationships: Managing accountability expectations through reputation. Public Administration Review, 77(1), $91-100$.

Burns, J. \& Scapens, R. (2000). Conceptualizing management accounting change: An institutional framework. Management Accounting Research, 11, 3-25.

Carpenter, D. (2010). Reputation and power: Organizational image and pharmaceutical regulation at the FDA. Princeton: Princeton University Press.

Contandriopoulos, D., Denis, J., Langley, A. \& Valette, A. (2004). Governance structures and political processes in a public system: Lessons from Quebec. Public Administration, 82(3), 627-655.

Denis, J.L., Ferlie, E. \& Van Gestel, N. (2015). Understanding hybridity in public organizations. Public Administration, 93(2), 273-289.

DiMaggio, P. \& Powell, W. (1991). Introduction, in W. W. Powell and P. J. DiMaggio (eds). The new institutionalism in organizational analysis. Chicago: University of Chicago Press.

Eyal, G. \& Pok, G. (2011). From a sociology of professions to a sociology of expertise. CAST Workshop on Security Expertise, University of Copenhagen, 6, 15-17. 
Fuller, S. (2017). Sociology as the post-truth science. BSA. Available at: https://www.britsoc.co.uk/about/latest-news/2017/august/sociology-as-the-post-truthscience/?utm_source=newsletterandutm_medium=emailandutm_campaign=august_ne wsandutm_content=steve_fuller

Garrety, K. (1998). Science, policy, and controversy in the cholesterol arena. Symbolic Interaction, 21(4), 401-424.

Gilad, S., Maor, M. \& Bloom, P. (2015). Organizational reputation, the content of public allegations, and regulatory communication. Journal of Public Administration Research and Theory, 25(2), 451-478.

Gulbrandsen, M. \& Smeby, J.C. (2005). Industry funding and university professors' research performance. Research Policy, 34(6), 932-950.

ICAI. (2014). How DFID learns. Available at: http://icai.independent.gov.uk/2014/04/04/icai-publishes-report-dfid-learns/.

Kislov, R., Hodgson, D. \& Boaden, R. (2016). Professionals as knowledge brokers: The limits of authority in healthcare collaboration. Public Administration, 94(2), 472-489.

Lasswell, H.D. (1948). The structure and function of communication in society. The Communication of Ideas, 37, 215-228.

Laudel, G. \& Gläser, J. (2007). Tensions between evaluations and communication practices. Journal of Higher Education Policy and Management, 28(3), 289-295.

Marnoch, G., McKee, L. \& Dinnie, N. (2000). Between organizations and institutions: Legitimacy and medical managers. Public Administration, 78(4), 967-987.

Mason, C., Kirkbride, J. \& Bryde, D. (2007). From stakeholders to institutions: The changing face of social enterprise governance theory from stakeholders to institutions. 
Management Decision, 45(2), 284-301.

Maor, M. (2016). Missing areas in the bureaucratic reputation framework. Politics and Governance, 4(2), 80-90.

McLennan, G. (2008). Disinterested, disengaged, useless: conservative or progressive idea of the university? Globalisation, Societies and Education, 6(2), 195-200.

Medvetz, T. (2012). Murky power: “think tanks" as boundary organizations: Rethinking power in organizations, institutions, and markets. Research in the Sociology of Organizations, 34, 113-133.

Medvetz, T. (2010). "Public policy is like having a vaudeville act": Languages of duty and difference among think tank-affiliated policy experts. Qualitative Sociology, 33(4), $549-562$.

Morrow, S.L. \& Smith, M.L. (2000). Qualitative research for counselling psychology, in D. Steven and R. Lent (eds). Handbook of counselling psychology. Hoboken: John Wiley and Sons Inc.

Nicholls, A. \& Cho, A. (2006). Social Entrepreneurship: The structuration of a field, in A. Nicholls (ed.). Social entrepreneurship: New models of sustainable social change. Oxford: Oxford University Press, 99-118.

Peters, G. \& Pierre, J. (1998). Governance without government? Rethinking public administration. Journal of Public Administration Research and Theory, 8(2), 223243.

Rauh, K. (2010). NGOs, Foreign Donors, and Organizational Processes: Passive NGO Recipients or Strategic Actors? McGill Sociological Review, 1, 29-45.

Sanderson, I. (2002). Evaluation, policy learning and evidence-based policy making. Public 
Administration, 80(1), 1-22.

Scott, R. (2014). Institutions and organizations: Ideas, interests, and identities, 4th edn. Thousand Oaks: SAGE.

Star, S.L. \& Griesemer, J.R. (1989). Institutional ecology, 'translations' and boundary objects: Amateurs and professionals in Berkeley's museum of vertebrate zoology 1907-39. Social Studies of Science, 19(3), 387-420.

Stampnitzky, L. (2013). Experts, states, and field theory: Learning from the peculiar case of terrorism expertise. Critique Internationale, 59, 89-104.

Stone, D. (2008). Global public policy, transnational policy communities, and their networks. Policy Studies Journal, 36(1), 19-38.

Suchman, M.C. (1995). Managing legitimacy: Strategic and institutional approaches. The Academy of Management Review, 20(3), 571-610.

Sullivan, H. (2011). “Truth” junkies: Using evaluation in UK public policy. Policy and Politics, 39(4), 499-512.

Tchillingrian, J. (2015). British think-tanks and dance of policy knowledge production. Unpublished thesis, University of Cambridge.

Young, J., Davis, T., Sherlock, S., Pasanen, T. \& Shaxson, L. (2015). Research for better aid: An evaluation of DFAT's investments. Available at: https://dfat.gov.au/aid/how-wemeasure- performance/ode/Documents/research-for-better-aid-an-evaluation-of-dfatsinvestments.pdf

Zucker, L.G. (1977). The role of institutionalization in cultural persistence. American Sociological Review, 42(5), 726-743.

This article is protected by copyright. All rights reserved. 
Williams Kate (Orcid ID: 0000-0002-2882-1068)

Attaining legitimacy in policy knowledge

TABLE 1. Strategies for attaining legitimacy

\begin{tabular}{lll}
\hline Strategy & Concern & Legitimacy \\
\hline Coherence in identity & Negotiating organizational identity & Cognitive \\
& Negotiating individual identity & \\
\hline Coherence in process & Maintaining independence & Moral \\
& Maintaining integrity & \\
& Maintaining transparency & Pragmatic \\
\hline Coherence in outcome & Creating the right type of products & \\
& Creating the right audience & \\
& Creating the right kind of impact & \\
\hline
\end{tabular}

TABLE 2. Strategies for achieving legitimacy and corresponding affordances

\begin{tabular}{llll}
\hline Coherence & Negotiated Elements & Legitimacy & Affordance \\
\hline \multirow{2}{*}{ Identity } & Negotiating organizational identity & Cognitive & Distinctiveness \\
& Negotiating individual identity & & \\
\hline \multirow{2}{*}{ Process } & Maintaining independence & & Credibility \\
& Maintaining integrity & Moral & \\
\hline
\end{tabular}

This article is protected by copyright. All rights reserved. 
Creating the right products

Outcome Creating the right audience Pragmatic Significance

Creating the right impact

\begin{tabular}{|c|c|c|}
\hline \multirow{2}{*}{\multicolumn{3}{|c|}{ TABLE 3. Illustrative examples for the key negotiated elements of each type of 'coherence' }} \\
\hline & & \\
\hline \multicolumn{3}{|c|}{ Coherence in identity (Cognitive legitimacy) } \\
\hline \multirow{20}{*}{$\begin{array}{l}\text { Negotiating } \\
\text { organizational } \\
\text { identity }\end{array}$} & EG1. & 'I also see the big advantage opening an institution like this, where \\
\hline & & there is still a relatively high degree of self-standing reflective work \\
\hline & & on development process, it's from critical heterodox perspective. \\
\hline & & And I think it's worth protecting that, because in policy-related \\
\hline & & research, there's a lot of complacency and talking up to the funders \\
\hline & & and running after different priorities'. (U15) \\
\hline & EG2. & 'Most of the programmes have to go where the money is. \\
\hline & & Obviously, money is provided by funders with specific views on \\
\hline & & specific sort of perspectives on the world ... People say [this \\
\hline & & organization] researches all, that [it] doesn't have an institutional \\
\hline & & position.... I don't know, I don't know if that's the case. I guess its \\
\hline & & maybe even less the case now because there's pressure to have a \\
\hline & & position and to engage with the media so you've got to adopt key \\
\hline & & messages etcetera'. (T12) \\
\hline & EG3. & 'So it's built on that sort of classic, I guess, Brookings Institution \\
\hline & & model of there not being a particular ideology the Institute \\
\hline & & promotes, and that individual scholars could choose their own \\
\hline & & position and argue it. Having said that, there's no doubt that there is \\
\hline & & broadly speaking a consensus on certain ideas within the Institute'. \\
\hline & & (T9) \\
\hline
\end{tabular}

This article is protected by copyright. All rights reserved. 
EG4. 'With [this organization] you always have to be neutral on certain subjects ... but those dynamics are super problematic in a multilateral organization where your funding partners are other organizations or other states ... but the way [the organization] is structured, the [sub-sections] have a relative autonomy, so your senior policy advisors currently and in the past had a lot of autonomy in looking at the kinds of questions that they wanted to promote, except that it needs to flow onto at some level on what country officers are asking'. (G21)

Negotiating
individual
identity

EG5. 'So if you want a brief outline as to how I go about deciding my priorities, I would say that there are three components. Number one is what I observe as problems in the world, number two, what seems to be of interest to the institution, and number three, what my various expertises are. If you will, numbers one and three are reflections of my bottom-up approach for me to make the decision, and number two will be top-down'. (G14)

EG6. 'We have annual research priorities set once a year, which we all get together and negotiate, because of our own interests, and get five - essentially five priorities, broad priorities that we are supposed to follow over the year and the commissioned work that we undertake or our own research is meant to fit under those sorts of broad themes. It doesn't have to. I mean we still have to make ourselves flexible to commission a piece or write a piece relatively quickly if something comes up like [particular] tensions even it's not under the broad priorities that we've already established. If it's something that needs to be, and put it into the policy package, so we do have exceptions. I don't have complete freedom but I certainly have many opportunities to import my ideas'. (T7)

EG7. 'They probably consider it formal, but it's more a get together. It's called a peer review process where we just sort of talk about some 
of the things to consider, however its informal in the sense that it's not binding in any way, what we say'. (G3)

EG8. 'I have been a little bit surprised at how much individual people have shaped this... It would be reasonable to think that a report put out by this institution, which is a huge bureaucratic leader in a field would be sort of highly vetted like it would sort of represent the collective, some sort of a collective opinion of what was really most important given the topic or something like that. I suppose I have been sort of surprised, or it has just been interesting, to see that the boundaries of this project, the parameters of it and the depth of it were very much shaped by a handful people who were working on it or who were important advisors'. (G15)

\section{Coherence in process (Moral legitimacy)}

Maintaining EG9. 'The work that we get through in dealing with industry partners is
independence
essentially consulting, private consulting. Obviously, we need to be
strategic about what sort of projects we bid for and the arguments
that we look at, we might do projects that have perhaps a quite
marginal impact on development but there are projects that allow us
to raise money ... In the research consultancy work we don't use
particularly advanced, high level modelling approaches simply
because it's not that important. The important feature doing
research-based consultancy policy advisory work is that the people
you're working with have a sense of ownership of what you're
doing'. (T6)


that sort of the tight coupling that happens between the research and the policy definitely leads to some pressure because people want to see their programme featured in a positive light. The administrative teams want things happening on the right timeline and so certainly there are pressures there that I think an independent researcher at a university setting would not face'. (G15)

Maintaining
integrity

EG11. 'At the end of the day there are differences between kind of funding resources that DFID provides as opposed to, you know, research councils or foundations, and so some would say DFID money comes with strings. But the strings are quite delicate, if there are any, in the sense that obviously, researchers have a choice about whether they want to apply for research funding and with that focus on, broadly, on areas which are close to their interest and are relevant to their policy and practice, but there are some who may not. Definitely some researchers who don't want to do that but they are not recalcitrant. So, they have to make a choice'. (G6)

EG12. 'Yeah so that's one shift and the other is you've got more freedom, I guess, you can say what you want. You don't have to have everything ... and it's less anonymous, it's more like at the end of the day it's your product. It's got your name on it whereas at the [multilateral] it's a more corporate effort'. (T1)

EG13. 'There are certainly concerns expressed about the type of sensitivities around the work that we do and we have to negotiate that. So, we try at all cost to ensure that we are presenting the work - the findings that we want to present and to give the messages we want to present. But there's always - I don't think I would say they would revoke our funding but there have been instances in the past where they have been unhappy that we have been at the centre for work that I have been directly involved in. I mean they have been unhappy with the type of research that we've been conducting 
before the results have been out. That's been expressed. I mean we resist very strongly'. (T5)

\section{Coherence in outcome (Pragmatic legitimacy)}

Creating the EG14. 'It's even more difficult for academics, we're not trained to have right type of that kind of outlook. Because their academic careers have mostly products been concerned with getting out research journals and their publication of research journals that will have an impact on the academic field which they have located, in terms of debates and, and advanced knowledge and all the rest. They are not used to going beyond that in talking to a larger audience, if you look at our website you'll see that in the early years we put out a lot of popular publications like little two-page developed viewpoints or fourpagers, policy briefs or research briefs, because the idea was we want to have an impact beyond academic circles, on these 10,000 people out there who are development specialists ... So, that was part of the movement beyond academia, having a broader popular impact, but you have to craft your publications accordingly'. (U16)

EG15. 'There are no incentives around the way my contract is constructed and there are big disincentives in terms of just you know the whole rigmarole around getting something from the point of what you feel is completion through to the point of publication in that peer review journal ... If you want policy impact you are not going to get it by waiting for something to be published in a peer review journal. But a lot of the pieces could be in principal, if you are willing to wait, they would need to be re-cast a bit, less colloquial, more literature surveys, more citing evidence at every turn. None of which is attractive but if you had to do it you could'. (T2)

Creating the right audience
EG16. 'I write a blog and I know that has been read probably thousands of times more than anything that I have written from an academic 
perspective. So, I am under no illusions that the [academic] work that I am doing is speaking to anything other than the narrow audience'. (U13)

EG17. 'We have a media person who is quite effective so we use social media very effectively to get the output out whether it's Facebook or Twitter plus traditional media. We do a lot of just interviews on traditional TV, news and media as well. It's basically through public channels rather than through back channels and through direct engagement. We hosted a workshop on [an initiative] so we are engaging directly with the people involved in the design of the follow-on mechanism. The last sort of avenue is that we provide a platform for a lot of visiting speakers ... there might be a meeting with Ministers or [agencies] and we will usually set up some sort of seminar or public lecture around that to give their views increased prominence and attract some media attention'. (T2)

Creating the right kind of impact
EG18. 'I was sent the [forms] from physics which had very clear key performance indictors around guessing which journals were going to be targeted for this, that and the other. I had to reframe ours, not to fit that, but to actually create slightly differently performance indicators around policy impact, public dialogue on the aid and development debate as being indicators as opposed to heavily weighted around publications. At the moment, we're still debating the key performance indicators for this grant, but it's a test case for me to see if the University is really going to live up to its rhetoric around wanting to do more of this kind of applied research and making a difference and building partnerships with the outside world as opposed to just making metrics that are largely academically based and which suit disciplinary kind of work'. (U6)

EG19. 'So something I find about academia is that there's not enough engagement with the sectors or the processes that are being 
researched. And for that reason, we often ask questions that have no validity because they either refer to tensions or conflicts that don't exist or they refer to practices that have not existed for years. And what happens is the research that is done in response is irrelevant, and it leads to the discrediting of academic research in the eyes of the very people that we should be trying to influence. Or it doesn't have the impacts on the ground in terms of, you know, reducing poverty, you know, getting more kids to school, reducing maternal mortality - it doesn't have those impacts because the research is just not relevant'. (T6)

EG20. 'I think it's important that it has an impact on policy. I find it sometimes difficult to separate these two things because in most of the cases when you have, when you do something that is relevant from development point of view, policy point of view, that has impact on academia in terms of having lots of impact on how people think about development economics and how people implement projects. It is very difficult to separate the two things'. (G13) 


\section{University Library}

\section{- M M N E R VA A gateway to Melbourne's research publications}

Minerva Access is the Institutional Repository of The University of Melbourne

\section{Author/s:}

Williams, $\mathrm{K}$

Title:

Three strategies for attaining legitimacy in policy knowledge: Coherence in identity, process and outcome

\section{Date:}

2018-03-01

\section{Citation:}

Williams, K. (2018). Three strategies for attaining legitimacy in policy knowledge: Coherence in identity, process and outcome. PUBLIC ADMINISTRATION, 96 (1), pp.53-69. https:// doi.org/10.1111/padm.12385.

Persistent Link:

http://hdl.handle.net/11343/285150 